\title{
A Provocation for Screendance as a Secular Space
}

Sumedha Bhattacharyya, Jindal School of Liberal arts and Humanities, O.P. Jindal University

Keywords: dance, secular, camera, pandemic, tradition, gender, duet with camera

The dancer and the camera do not exist in a vacuum

They co-exist in a space that is not transparent and innocent ${ }^{1}$

but complex and layered socio-political and religious structures of power.

They are imbued with Power

Power drives, escalates, and charges us like a field condition.

Dance and camera exist in field conditions of Power.

Power is intrinsically connected to how the dancer and the camera interact.

Dance for Camera, Dance on Camera, Dance with Camera

These are connecting words that imply power and non-transparency.

Such is a world that the pandemic saw

Rights of being human, forcibly taken,

to solemnly resolve to constitute a Secular country, ${ }^{2}$

Together, we, the people of the world, are receiving a continuous assault on values of secularism and democracy.

We need to talk about the Secular, as citizens first and dancers later

Secular is not anti-somereligion

It is for-everyreligion

I write here, today, navigating and questioning the Secular in Screendance,

Why do I always see an Indian dancing in front of a beautiful monument 
Like a museum doll,

Mysterious, untouched, never up-close.

A tradition, in wide shot of her full body(mostly) in a beautiful costume or too many beautiful shots, from different viewpoints

A tradition, untouched.

Another tradition, in close-up shot of her beautiful eyes bold make up

The male gaze, mostly white

Shooting an exotic dance of the Sacred

Ah! Beautiful, they say

So, where is the place for grotesque in Indian classical dance?

Doesn't the doll feel pain?

How do we share difficult topics of pain, ageing and decay?

through the camera behind the laborious footwork of Kathak?

Is there room for sharing female pleasure?

Are we classical dancing bodies all the time?

What about our homes?

What kind of everyday myths we tell each other?

Is that all our identity been reduced to,

The sacred?

The idea is to submit, to perfect, to perfect beauty.

My body is trained in the beautiful form of Kathak

They say is the storyteller.

Storytelling about the Gods.

The male gods

Brahma

Vishnu

Mahesh 
Krishna

Ram

I could not relate to the dancing and the reality outside of it.

A lot of it is maybe because being a female body

A body being looked at

Gazed

Through a lens,

Lens of an audience

a Guru,

a parent,

a frame

an angle,

an aperture.

With so many layers,

A female, brown, Indian body

This body is trying to explore beyond what is the tradition.

What is this space?

That I constantly negotiate between the observer and the observed. ${ }^{3}$

Dance has been witnessing an unprecedented relatedness and a probable slow aversion to technology during the Covid-19 pandemic. It has also been during this entangled time consciousness, that we have been seeing a form of "organised loneliness"4 emerge with our screens. For me, the seed of screendance began in 2018, which was planted during my Master's program. ${ }^{5}$ Returning to India that year, growing through different experiments ${ }^{6}$ with the camera, my mind wandered around questions like: What is Screendance in India? Does anyone know of screendance here in India? Why does anyone need to know about screendance in India? Does it have another name here? How can I belong to something that has not been researched and practiced here? Or maybe it has been, but in a different path. In India where we have a history of a strong and rich visual culture, where does one begin to locate and perceive screendance, if at all? 
During the pandemic in April 2020, a month after lockdown in India, I received a oneyear Practice-based Art research fellowship to study the relationship in-between the dancer and the camera with my project titled Duet with Camera. The first and foremost way to work around this project was for me to get out of the bubble of a privileged dancer, happy with my discipline, with the privilege of possessing a camera and a stable internet connection. This could happen only when one extends a hand, literally opens the screen, and drops in a text: conversation became my inquiry. Being a South Asian, and an interested student in screendance, already conjures up so many images (mostly stereotypical) as you read me today. The loneliness of working with screendance even after significant playing with the repertoire, amidst the pandemic, triggered an uneasiness to understand so many questions bottled up with curiosity, wonder, nervousness and fear of missing out anxieties. I found a post on Instagram on a short notice, interestingly called Screendance: Diversity \& Representation Matters. ${ }^{7}$ These conversations were already taking place in the Global North, but only this time, it became global. The pandemic renewed the urgency of these conversations. India witnessed a sudden semiotic turn towards representation and diversity conversations.

Most international film festivals became accessible and online like Movimiento en Movimiento Festival 2020, Souci Festival for Dance Cinema 2020, Rogue Dancer Festival 2021, Screen.Dance Scotland Festival Artist presentation category 2021, and the upcoming Kinesthesia Festival. All these festivals I had applied to with minimal fee or no fee at all and had also been accepted for most of the above festivals. This kind of inclusion also challenged the dominantly elite and western viewpoint of screendance and how we can rethink the accessibility of art, today. Was this semiotic turn of events merely, as The Care Manifesto indicates, a form of "carewashing," as opposed to genuine care? Was the inclusion and diversity term selectively carried out to increase the legitimacy of the festival, coming forth as socially responsible, while contributing to more inequity and thus privilege and elite-ness in screendance. The conference for me, proved to be a great resource for networking to start a conversation with familiar strangers, but also left me constantly perturbed: Why there had not been any screendance films presented (not re-presented) from India? Why was I the only one from India in that conference? I am also speaking to the landscape and lack of festival presence in the screendance locale. In the early discoveries of my project, I noticed the absence of India's own dance film/screendance/dance on camera festival and its negligible, linear, and exotic participation in these international festivals

My creative process of dance for the camera germinates from a nomadic subjectivity and embodied experience in the Indian classical form Kathak and the hybrid art form of screendance. My provocation stems from a space that asks how the traditional modes of presentation of the Indian classical body through a male, white, exotic lens can be disrupted, not only in performance, but in the creative process of knowing, imagining and making screendance. Why has the representation of screendance film from India, been next to negligible, even after having such a rich culture of both dance and film? Is 
India too big to begin, or too mysterious to never begin? In the dance and film history of India, Indian classical dance is most often captured using the camera as a passive observer to document the autobiographical narrative of a dancer and recorded only the full-body dancing from a frontal perspective. However, there have been many films that had utilized new editing strategies of filming dance in India with co-presence of a dance and cinema aesthetic, like Uday Shankar's Kalpana (1948), Pramod Pati's Explorer (1968), a ghost dance sequence from Satyajit Ray's Goopi Gyne and Bagha Byne (1968). Why is this history neglected as a part of screendance? Screendance as a term is a very new one in the dance and film community of India, but maybe because it is something that comes from the Global North.

As a part of my practice-based art fellowship project Duet with Camera, I have been researching this relationship and the space that dancer and the camera create, on an embodied level as well as in a community of practice. Especially within the framework of radical uncertainty, transition to locked environments, and crisis of belonging, Duet with Camera was born on Instagram as an accessible, inclusive, and democratic space for documenting students ${ }^{\prime 9}$ process of working with the camera. This Instagram page thus became an awareness platform on screendance, provocations, which guided its way to discover new conversations, experiments and collaborations between movement and camera practitioners. One of the initiatives was Camera and I, a selfdesigned virtual residency on Instagram, ${ }^{10}$ that brings different movement and camera practitioners in India, to create a visual knowledge mapping of their artistic processes with the camera. Duet with Camera, today, envisions a research-creation space which aims to galvanize and activate these dialogues and create a local yet global pedagogy of screendance.

As the author Arundhati Roy rightly quotes "The pandemic is a portal, a gateway between one world and the next."11 We need to re-think, re-visit, re-search and re-write screendance. How can the camera go beyond a passive, ethnographic, or historical capturing object? How can the space and spectatorship of Indian classical dance go beyond what is considered as sacred? Can camera become a space for a performance of protest? Can screendance become a secular space? By secular I mean challenging what has been legitimized as "technique" in Indian classical dance and conventional filmmaking practices, including Bollywood, which further galvanises/mobilizes a community space by articulating dialogues of experimentation in-between dance and camera practitioners. By Screendance as a secular space, I also mean a provocation for an unsurveilled, experimentative and creative environment that is anti-fundamentalist, especially in the current political climate. How can embodying the secular, instigate new practices to relook, re-visit and re-imagine screendance 2) galvanise/mobilize a community space and thus 3) democratize screendance learning and dissemination through independent festivals. Seeing the dearth of Dance on Camera/Screendance India's participation in dance film, Duet with Camera has been aiding in the upcoming Body and Lens International Screen(ing) Dance Festival and Seminar $2021^{12}$ conceptualized by Dr. 
Urmimala Sarkar. ${ }^{13}$ I look forward to reaching out to the existing screendance community, educators curators, consultants, sponsors guides, and mentors as working towards this festival and many more to discover.

\section{Biography}

Author Sumedha Bhattacharyya is an interdisciplinary dance artist, educator, researcher, dance filmmaker and a primary caregiver. She is a faculty (Academic Tutor and Teaching and research for Intellectual Pursuit (TRIP) Fellow at Jindal School of Liberal arts and Humanities, India. Her artistic practice brings a fresh viewership of the camera as an artistic process for caring and contemplation, an enabling space for intergenerational bonding, and a narrative tool for dance pedagogy which challenges the existing formal qualities of 'seeing' dance. She is an awardee of Kolkata Centre for Creativity Art Fellowship in Dance with her embodied practice-based research project Duet with Camera that explores the space and spectatorship in-between the dancer and the camera.

Email: sbhattacharyya1@jgu.edu.in

Website: www.sumedhabhattacharyya.com ; http://www.duetwithcamera.com/

https://youngindiafellowship.academia.edu/Sumedha

\section{Notes}

${ }^{1}$ This is a PhD dissertation by Valerie Briginshaw called "Dance, Space and Subjectivity."

${ }^{2}$ The words as quoted in the Preamble of our Indian Constitution.

${ }^{3}$ This issue was published in an online magazine called Someother Magazine on December $30^{\text {th }}, 2020$. The issue was based on the diverse forms in which surveillance transpires around us in the physical and the virtual dimension

${ }^{4}$ As defined by The Care Collective, Chatzidakis, et al., in The Care Manifesto.

${ }^{5}$ It is a two-year Erasmus Mundus Masters in Dance Knowledge, Practice and Heritage which started in 2016-2018 https://www.ntnu.edu/studies/choreomundus. The module was called Mediated Choreography taught by Dr Heike Salzer. 
${ }^{6}$ For example: Saraab, a collaborative film by Sumedha Bhattacharyya and Hediye Azma 2018; Touch the Sound, a Screendance video as commissioned by Flame University, Pune India 2019; Body as Archive, a curatorial project with Curatorial intensive South Asia 2018 with Khoj International Artists Organisation in India.

${ }^{7}$ The link to the event https://www.gabrichrista.com/upcoming/vrystaat-arts-festival

${ }^{8}$ This project was one-year fellowship project where I was selected by arts organization Kolkata Centre for Creativity. The website shows the journey of the last year and current processes www.duetwithcamera.com

9 These were undergraduate students from a co-curricular course I self-designed and conducted called Screendance at Ashoka University, India. This course was a part of the Performing arts department, run by Justin McCarthy. He is the also the Head of the Department for Co-curricular, Ashoka University.

10 The Camera and I Instagram takeover/ virtual residency on http://www.instagram.com/duetwithcamera was initiated as a method of understanding Screendance in India. Through this initiative, a visual knowledgemapping and visual archiving of each practitioners' insights, processes, inspirations and vulnerabilities of working with dance and/or camera vis-a-vis the moving body and the moving image.

${ }^{11}$ Arundhati Roy is a leading Indian author best known for her novel The God of Small Things. She talks about how the pandemic threatens India, and what should the world do next. https://www.ft.com/content/10d8f5e8-74eb-11ea-95fe-fcd274e920ca

12 The upcoming Body and Lens Festival and Seminar as scheduled for July 2021 and November 2021, dreams of creating a pedagogy for Screen dance / Dance for Camera a space for a series of three webinar / seminars to formulate a pedagogic discourse around a pedagogy for teaching Screen dance in India https://www.duetwithcamera.com/body-and-lens-festival2021. The festival is organized by Koushik Podder in Sastrika Unit of Performing arts and Leo's Lions Production Company.

${ }^{13}$ Dr. Urmimala Sarkar is an Associate Professor of Theatre and Performance Studies, at the School of Arts and Aesthetics in JNU, New Delhi. She is a dancer/choreographer trained in Uday Shankar style of Creative dance, Kathakali, and Manipuri at Uday Shankar India Culture Centre. Her current work is on changing landscapes of dance in India, Sex-trafficking and designing of survival processes for survivors of trafficking, and politics of performance. She is also a visiting faculty at the Tata Institute of Social Sciences, teaching a module on "Dance and Movement Therapy." She is currently the President of World Dance Alliance Asia Pacific, and one of the Directors of the Broad of Kolkata Sanved - an organization that works with women survivors of violence. 


\section{References}

Bhattacharyya, Sumedha. "Duet with Camera" Someother Magazine. I see you. Posted 30 December 2020. https://someothermag.files.wordpress.com/2020/12/ someothermag_issue2_iseeyou_.pdf

"Body as Archive" (2018). Dir and Curator. Sumedha Bhattacharyya and Hediyeh Azma.

Briginshaw, Valerie. "Dance, Space and Subjectivity." PhD dissertation. University of Southampton, 2001.

Chatzidakis, Andreas, Jamie Hakim, Jo Littler, Catherine Rottenberg, and Lynne Segal. The Care Manifesto: The Politics of Interdependence. London: Verso, 2020.

“Kalpana." $\quad$ Dir. Uday $\quad$ Shankar $1948 . \quad$ YouTube. https://www.youtube.com/watch?v=S6hnsycStbY\&t=851s

"Goopy Gyne Bagha Byne" Dir. Satyajit Ray 1968. YouTube. https://www.youtube.com/watch?v=OWxV_qCf2zE\&t=309s

Roy, Arundhati. "The Pandemic is a portal." Financial Times. Posted 3 April 2020. https://www.ft.com/content/10d8f5e8-74eb-11ea-95fe-fcd274e920ca

"Saraab" Dir. Hediyeh Azma. Dir. of photography Sumedha Bhattacharyya. 2018. Vimeo. https://vimeo.com/299854315

“The Explorer." Dir. Pramod Pati. 1968. YouTube. https://www.youtube.com/watch?v=wiWIUEOaFuQ\&t=322s

"Touch the Sound." Dir and Perf. Sumedha Bhattacharyya. 2019. Vimeo. Installation. https://vimeo.com/344758115 